\title{
Soil Water Balance and Vegetation Dynamics in a Semi-arid Mediterranean Ecosystem ${ }^{+}$
}

\author{
Ioannis N. Daliakopoulos ${ }^{1, *}$, Ioanna Panagea ${ }^{2}$, Luca Brocca ${ }^{3}$ and Erik van den Elsen 4 \\ 1 Department of Agriculture, Hellenic Mediterranean University, 71410 Crete, Greece \\ 2 Division of Soil and Water Management, Katholieke Universiteit Leuven, 3001 Heverlee, Belgium; \\ ioanna.panagea@kuleuven.be \\ 3 Research Institute for Geo-Hydrological Protection, National Research Council, 06128 Perugia, Italy; \\ luca.brocca@irpi.cnr.it \\ 4 Team Soil, Water and Land Use, Wageningen Environmental Research, Wageningen University and \\ Research (WUR), P.O. Box 47, 6700AA Wageningen, The Netherlands; Erik.vandenelsen@wur.nl \\ * Correspondence: idaliak@hmu.gr \\ † Presented at TERRAenVISION 2019, Barcelona, Spain, 2-7 September 2019.
}

Published: 25 May 2020

Keywords: soil moisture; time-domain reflectrometry; climate change; water balance model; Mediterranean

Under arid conditions, where water availability is the limiting factor for plant survival, water balance models can be used to explain vegetation dynamics. Here we analyze for the first time measurements from the precipitation exclusion experiment of the CASCADE Project [1] study site of Messara Valley, in Crete, Greece. The site is located in a marginal grazing land of patchy macchia vegetation on the fringe of the most important agricultural region of the island. Soil water content was monitored under and outside the canopy of 3 control Hyparrhenia hirta plants at two depths (2.5 and $15.0 \mathrm{~cm}$ below ground) using 12 EC-5 time-domain reflectrometry (TDR) sensors. Measurements were employed to calibrate a simple water balance model that uses rainfall and air temperature as input to predict soil moisture conditions [2]. Results show that the model can capture and quantify the significant effect of shallow rooted macchia patches on soil properties that control water content at the top $2.5 \mathrm{~cm}$ of soil during the drying process. On the other hand, at the deeper soil layer $(15.0 \mathrm{~cm})$, vegetation presence effect was negligible. An analysis of the model sensitivity to meteorological variables showed that surface soil under canopy was easiest to perturb by both precipitation and temperature changes during the wet season (October-April), part of which also coincides with a critical growing stage of the macchia vegetation. Following the climate change patterns foreseen for the Mediterranean [3], showing a precipitation reduction in the area of $10 \%$ and a temperature increase of $2{ }^{\circ} \mathrm{C}$, we predict a reduction of soil moisture by about $15 \%$ during the wet season. Modeling results will be used as background data for the precipitation exclusion experiment that aims to identify sudden changes in ecosystem structure and function caused by climatic shifts.

Acknowledgments: Experimental setup and measurements leading to this research were conducted during the CASCADE Project that was funded by the European Commission FP7 program, ENV.2011.2.1.4-2"Behaviour of ecosystems, thresholds and tipping points", EU Grant agreement: 283068. Modeling and analysis were co-financed by the European Union and Greek national funds through the Operational Program Competitiveness, Entrepreneurship and Innovation, under the call RESEARCH-CREATE-INNOVATE (project code: T1EDK-03372). 


\section{References}

1. Daliakopoulos, I.N.; Panagea, S.I.; Tsanis, I.K.; Grillakis, M.G.; Koutroulis, A.G.; Hessel, R.; Mayor, A.G.; Ritsema, C.J. Yield Response of Mediterranean Rangelands under a Changing Climate. Land Degrad. Dev. 2017, 28, 1962-1972, doi:10.1002/ldr.2717.

2. Brocca, L.; Melone, F.; Moramarco, T. On the estimation of antecedent wetness conditions in rainfall-runoff modelling. Hydrol. Process. 2008, 22, 629-642, doi:10.1002/hyp.6629.

3. Koutroulis, A.G.; Grillakis, M.G.; Daliakopoulos, I.N.; Tsanis, I.K.; Jacob, D. Cross sectoral impacts on water availability at $+2{ }^{\circ} \mathrm{C}$ and $+3{ }^{\circ} \mathrm{C}$ for east Mediterranean island states: the case of Crete. J. Hydrol. 2015, 532, 16-28, doi:10.1016/j.jhydrol.2015.11.015.

(C) 2020 by the authors. Licensee MDPI, Basel, Switzerland. This article is an open access article distributed under the terms and conditions of the Creative Commons Attribution (CC BY) license (http://creativecommons.org/licenses/by/4.0/). 